\title{
Lightning Protection of High-performance Photovoltaic Power Plants: Issues of Parts to Be Covered by the Lightning Protection System
}

\author{
Zoltán Tóth", István Kiss, Bálint Németh¹, István Berta \\ 1 Department of Electric Power Engineering, Faculty of Electrical Engineering and Informatics, Budapest University of Technology \\ and Economics, H-1111 Budapest, Egry József utca 18., Hungary \\ * Corresponding author, e-mail: toth.zoltan@vet.bme.hu
}

Received: 02 November 2020, Accepted: 12 January 2021, Published online: 02 February 2021

\begin{abstract}
This paper aims to represent when the primary lightning protection is not necessary for a photovoltaic power plant with a special dimension if the different security objects are not negligible during the probability and risk calculations. The calculations were made using the Probability Modulated Attractive Volume theory which is capable of special, complicated, or huge structures and objects like a high-performance photovoltaic park.
\end{abstract}

Keywords

lightning protection, photovoltaic, PV power plants, renewable energy sources

\section{Introduction}

Several types of power plants convert renewable energy into electricity, such as wind power, photovoltaic (PV) power, geothermal power, or biomass power. In Hungary, wind power capacity has not increased in recent years due to a previous legal restriction (see Fig. 1 [1, 2]). In contrast, PV capacities drastically increase their share in the energy mix and within the Hungarian electricity system (see Fig. $2[1,2]$ ).

PV power plants can be divided into two cases:

- small household-scale power plants that are not subject to a permit $\left(P_{\text {built-in }} \leq 50 \mathrm{kWp}\right)$ and

- licensed power plants $\left(P_{\text {built-in }}>50 \mathrm{kWp}\right)$.

For the purposes of our article, the latter power plant types are interesting, which can generally be considered to be located in a large area and are installed on a large flat or hill or hillside. Compared to conventional power plant types, these systems do not need to follow a schedule with the same rigor, as production is sufficiently affected by the weather to make it nearly impossible. Of course, additional battery packs would be an alternative to the latter in the future.

In contrast to wind power plants, the classic Lightning Protection (LP) design methods can be applied in the case of PV power plants. The problem is not caused by the large scale of these power plant types - which will be described in a later, Section $3-$, but by the fact that economic

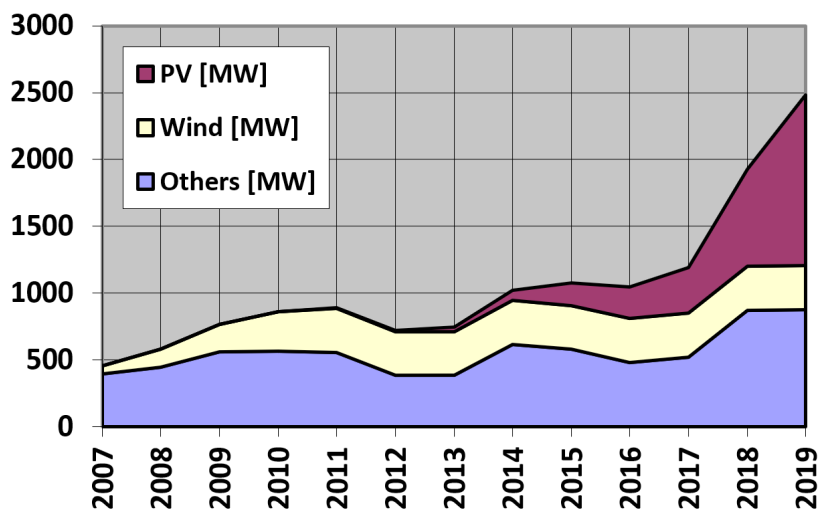

Fig. 1 The capacity of the Hungarian electricity system from renewable energy sources in MW on an annual basis $[1,2]$.

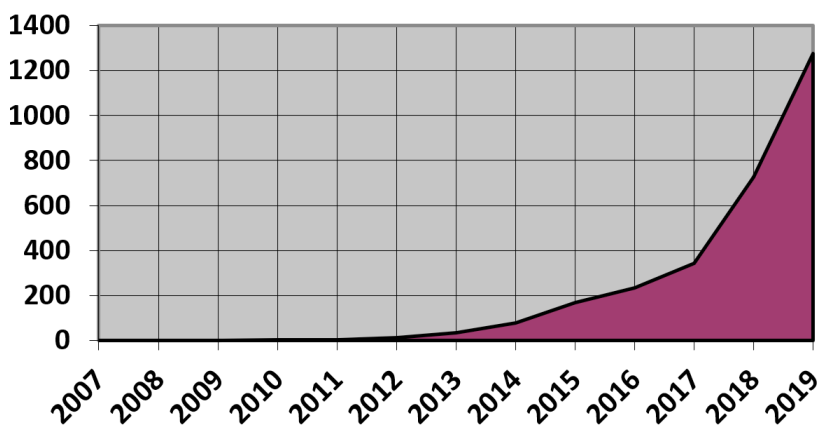

Fig. 2 The photovoltaic capacity of the Hungarian electricity system in MW on an annual basis $[1,2]$. 
(reducing environmental impact and cost-effective on a human scale) and adequate primary lightning protection requires a new approach that is only possible based on scientifically substantiated research results.

It is possible to come across this topic in several literatures where the need for primary lightning protection is raised or the most effective solution is tried. [3-5] Among other things, the authors published their publication and journal article on this topic $[6,7]$.

In the case of large-scale PV systems (Fig. 3), primary lightning protection is not necessary under the given conditions and extent, it is negligible. Secondary lightning protection is significant for plans with such large dimensions in all cases.

\section{About the used method for the calculation}

The Probability Modulated Attractive Space (PMAS) theory [8-10] describes the relationship between a given arrangement and attractive spaces. These are pieces of space that contain a set of points belonging to a given object that is closer to the selected object in the given finite space. Expressed in the language of mathematics, that part of space contains the points of the differential circular integral where $0 \leq P \leq 0.5$. All this statement is valid with the addition that the location of this space is polarity-dependent, which has been previously demonstrated experimentally [10] and proved in practice by a large number of observational data. This value is $\varepsilon>1$ for positive polarity and $\varepsilon<1$ for negative polarity. Where $\varepsilon=z / h$, that is, $z$ as the given space point and $h$ as the height of the object's vertex relative to the plane (Fig. 4).

The basis of PMAS theory is the reference point. It is possible to write several relationships between the orientation point and the orientation distance, but the following, Eq. (3) best approximates. Usually, a more straightforward form of this is used, which is satisfactory for low objects.

From the orientation point, it taps into that object with the given probability. This value can be characterized by $\beta$ (striking factor). In reality, the impact factor varies continuously between 0 and 1 , but it is mathematically simpler to determine the attraction space interface if it is

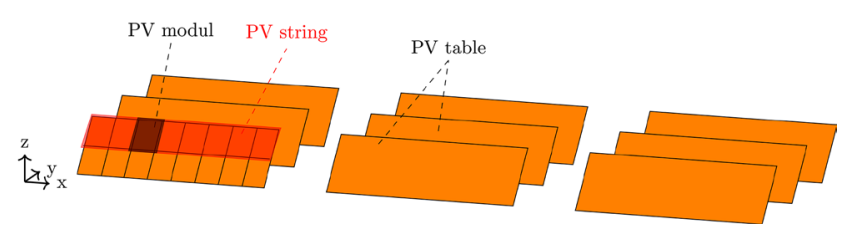

Fig. 3 General structure and parts of a PV park without server and control units.

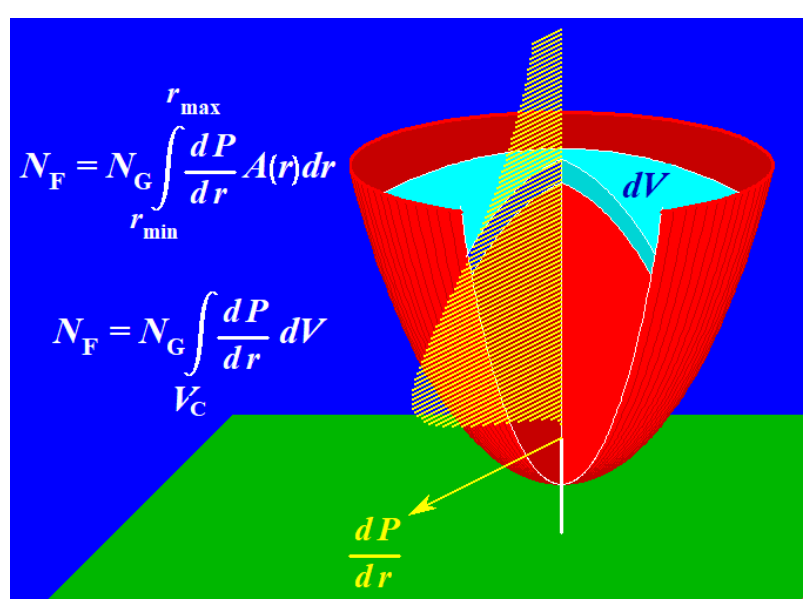

Fig. 4 The theory of attractive space (based on [8]).

taken as 0.5 . A further consequence of the simplification is that the part inside the attraction space is $\beta=1$, and the part outside it is $\beta=0$.

Equation (1) describes the lightning density for the attractive space, while Eq. (2) gives the value of $d P / d r$ (Fig. 5) for the given point.

$$
\begin{aligned}
& N_{F_{a}}=N_{G} \int_{V_{a}} \frac{d P}{d r} d V \\
& d P / d r=\frac{k p}{\sqrt{r \pi}} e^{-\frac{1}{2} k^{2} p^{2} \ln \left(r / r_{m}\right)^{2}} \\
& I / I_{m}=\left(r / r_{m}\right)^{p}
\end{aligned}
$$

where $P$ is the probability of the strike in the $r$ point; $k$ is a parameter which depends on the polarity of the lightning; $p$ is a parameter, always between 1.2 and 2 [11] (the exponent of the $\left.I / I_{m}=\left(r / r_{m}\right)^{p}\right) ; r_{m}$ is the median value of the orientation distance in meter; $r$ is orientation distance in meter; $N_{F_{a}}$ is the density as ground flash per $\mathrm{km}^{2}$ per year for the attractive volume; $I_{m}$ is the median of the lightning current in $\mathrm{kA}$; $I$ is the lightning current in $\mathrm{kA}$.

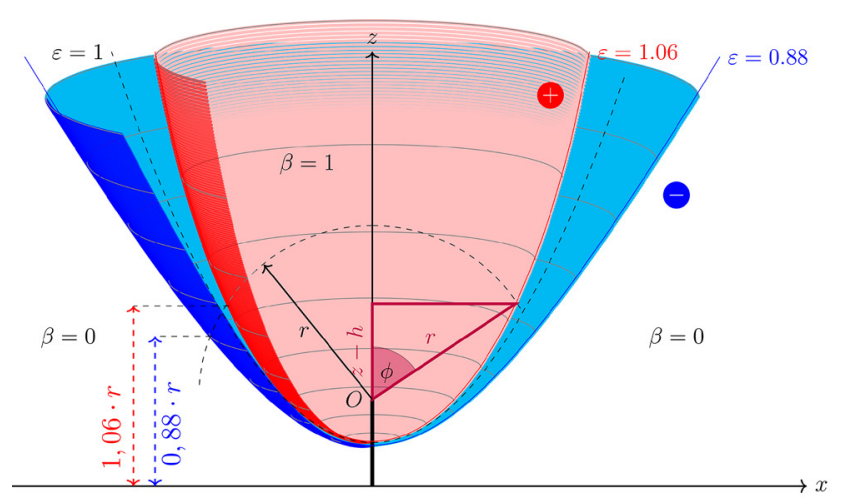

Fig. 5 The theory of attractive space for a high tower [8]. 


\section{Optimal (safe and economical) protection of photovoltaic power plants against the primary and secondary effects of lightning strikes}

PV systems are covered by IEC 62305 [12] for lightning protection design. This is true even if the talk is about a very large-scale and high-performance PV system. Starting from the standard, the issue was also examined by Rousseau and Kern [13], who came to a similar conclusion, relying strictly on the standard, to establish a set of conditions under which they need for secondary LP could even be questioned. The Fig. 6 shows the logic of the standard in how it approaches the issue. A protection level is selected first (e.g. LPS III) that will be appropriate for the risk calculation, and if not, the calculation should start from the beginning for a higher level of protection (e.g. LPS II).

This topic is addressed in more detailed in the authors' previous article [14]. In short: from the authors' point of view, it is necessary to calculate $R_{4}$, the risk of losing economic value $\left(P<10^{-3}\right)$.

\section{Characteristic properties of photovoltaic power plants due to their special geometry}

PV power plants can be interpreted as a special arrangement compared to traditional buildings and other built objects. First, these plants occupy a large floor area, and the second area is relatively low buildings are located. The occupied floor area increases in proportion to the installed capacity of the power plant. During installation, the account must be taken of the terrain conditions, which in many cases vary due to a large extent, such as the angle of the soil, its material, etc., and the effect of the shading applied by each sub-object.

The arrangement is also special in that it is made up of similar components. These units form larger sets, or there are variable but mostly similar distances between them due to the ones listed earlier. If we compare the case of a solar power plant actually constructed (with the distances between the components) with a theoretical case (without gaps between the individual solar panels), we get the result that the gaps negatively increase the occurrence of a possible lightning strike. This is because, in PV power plants, the edges of the connected system (Fig. 7) of batteries are most exposed to the increased lightning protection risk.

Examining only the standardized procedures, the need to install primary lightning protection cannot be questioned. According to the standard, the system of installed lightning protection receivers is examined during both the initial and periodic inspections, when the question of whether the installed system meets the expected level of protection must be answered. These tests do not take into account objects that are found in all real cases in the area of the PV power plant or its surroundings (e.g., security fences, poles holding security cameras, lighting poles). However, these structures could be used as primary lightning protection receivers, and thus the level of risk could be classified lower. This is also supported by calculations based on the PMAS theory. Based on this line of reasoning, a modified calculation methodology can provide an answer to the question of whether primary lightning protection is necessary for a given arrangement and, if so, what level of protection should be applied, possibly deviating from the usual practice.

\section{Security devices as part of lightning protection}

Examining only standardized procedures does not call into question the need to install primary lightning protection. The system of lightning protection traps installed for this reason is examined during both the initial and periodic reviews when the question of whether the system installed is adequate in terms of the expected level of protection must be answered. These studies do not take into account every single object in the environment where the security fence should be considered as a primary lightning protection receiver, thus reducing the level of risk.

This is also supported by the calculation based on the PMAS theory [15], according to a modified calculation methodology that can answer the given arrangement whether primary lightning protection is necessary and, if so, what level of protection should be applied, possibly deviating from the usual practice.

In the case of PV power plants, damage not only to PV panels but also to other systems that may be sensitive to overvoltages (electronics, protections, drives, and metering systems) can cause high additional costs. The provision of secondary lightning protection to these modules is absolutely necessary for safe operation.

\section{Results of the PMAS calculation}

Calculations were performed with and without a fence on the probability of lightning for a given current being struck on a given area of space. Space was divided into two parts:

- roof and

- PV tables (all). 


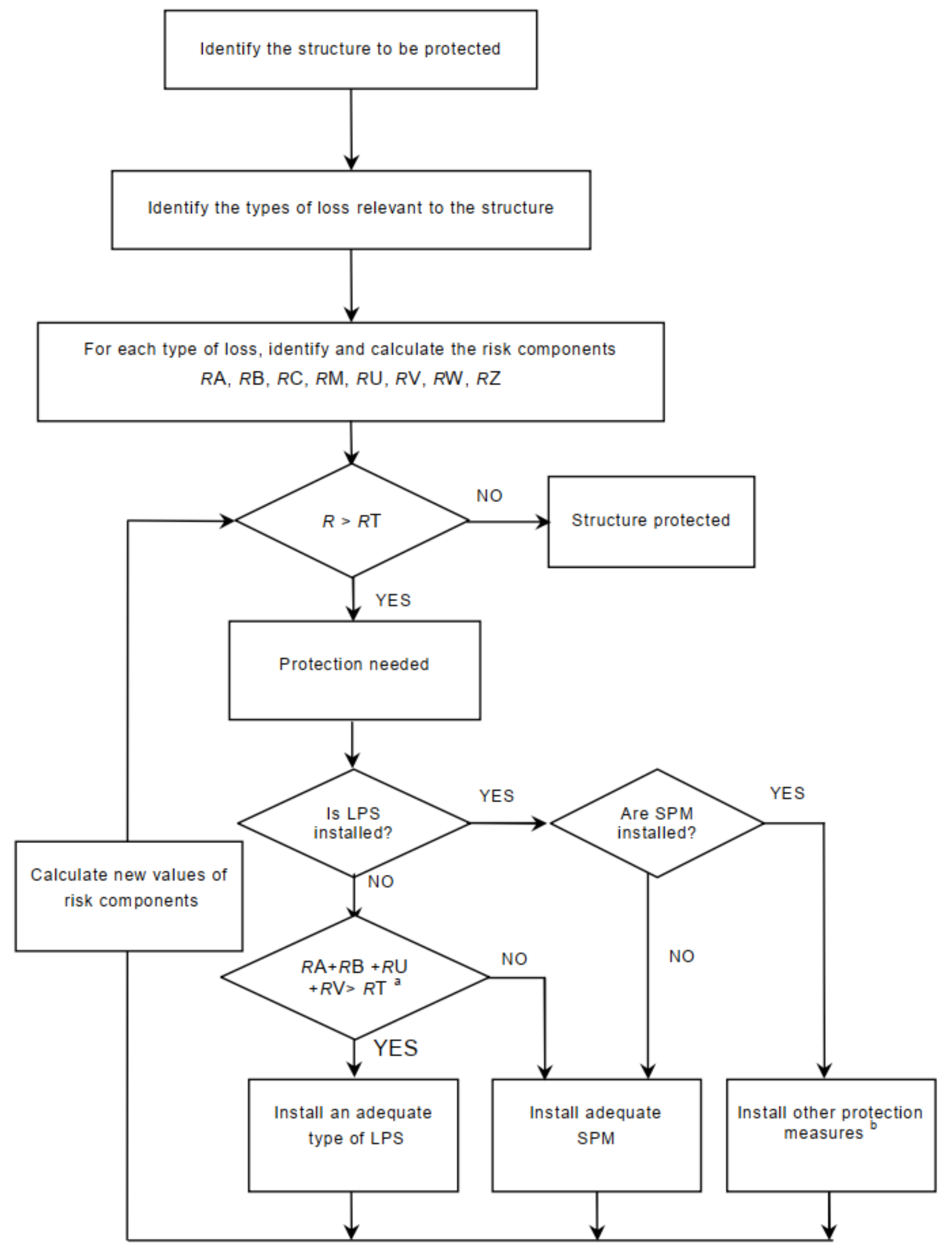

Fig. 6 The flowchart of the risk calculation in the standard [12]. 


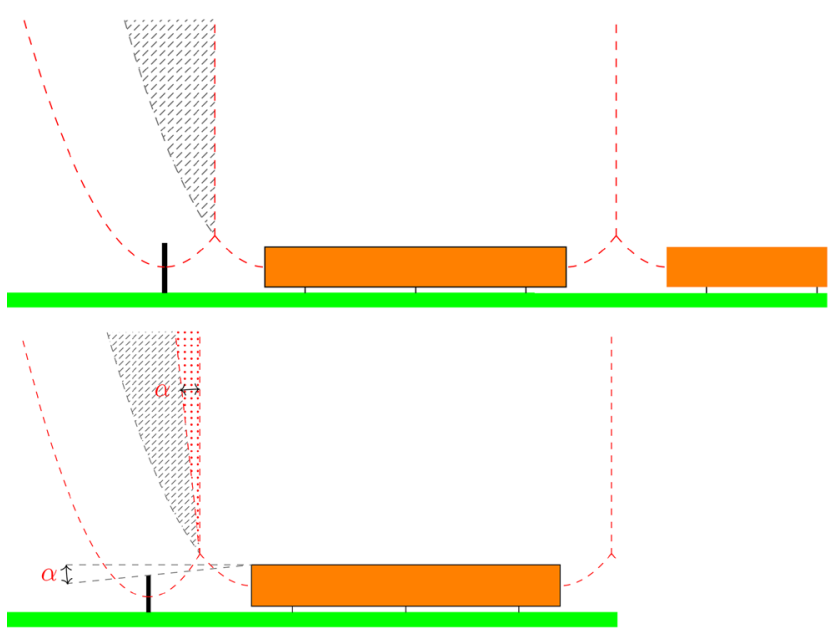

Fig. 7 The security fence with its effect on the attraction space during the graphical display of PMAS theory for the fence with the same and lower high as the PV panels.

The result of this is shown in Fig. 8. The calculation was done by ignoring the fence and comparing it to the size of the difference between the two (see Fig. 9).

It is clear how much difference there is between the two cases. At lower currents, the shielding effect is reduced from $20 \%$ to $60 \%$, while at higher currents, the shielding effect is reduced.

\subsection{The change in risk as a function of the dimensions of the PV cells}

Performing the PMAS calculation for specific solar systems with regular, repetitive cells can be used to read a kind of trend. A maximum lightning current (Table 1) is determined for the given lightning protection level, which must be calculated for the given degree. In practice, this does not mean that higher lightning currents cannot occur,

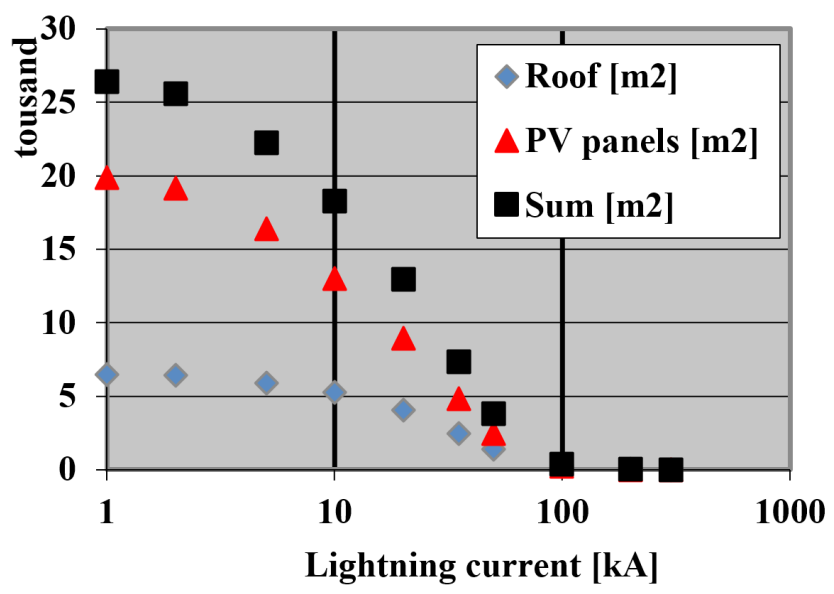

Fig. 8 The results of the PMAS calculation for an imaginary $8 \times 12$ table PV park [14].

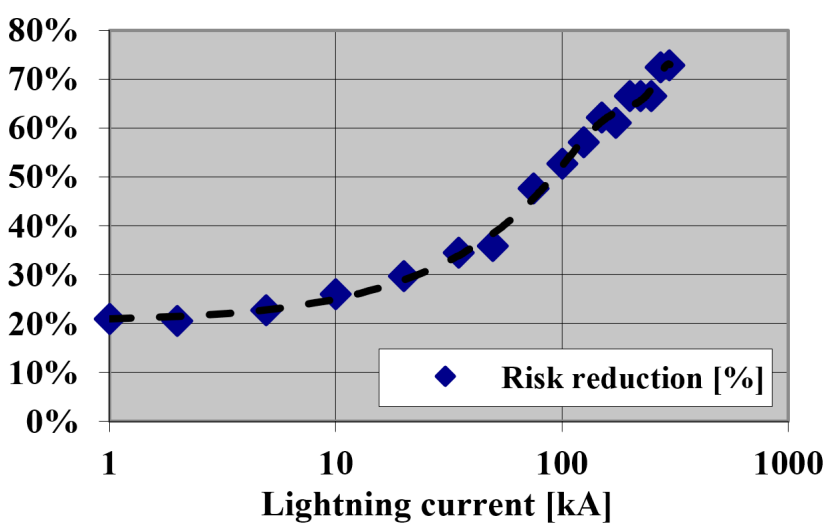

Fig. 9 Percentage of risk reduction for an imaginary $8 \times 12$ table PV park based on the results of the PMAS calculation compared to the case without a fence.

Table 1 Maximum values for the radius of the rolling sphere and the size of the grid according to each LPL [12].

\begin{tabular}{|c|c|c|c|}
\hline \multirow[b]{2}{*}{$\begin{array}{l}\text { Class of } \\
\text { LPS/LPL }\end{array}$} & \multicolumn{2}{|c|}{ Protection method } & \multirow{2}{*}{$\begin{array}{l}\text { Maximum lightning } \\
\text { current } I_{0 / \max }[\mathrm{kA}] *\end{array}$} \\
\hline & $\begin{array}{l}\text { Rolling sphere } \\
\text { radius } r[\mathrm{~m}]\end{array}$ & $\begin{array}{c}\text { Mesh size } \\
w_{m}[\mathrm{~m}]\end{array}$ & \\
\hline I & 20 & $5 \times 5$ & 200 \\
\hline II & 30 & $10 \times 10$ & 150 \\
\hline III & 45 & $15 \times 15$ & \multirow{2}{*}{100} \\
\hline IV & 60 & $20 \times 20$ & \\
\hline
\end{tabular}

* The worst-case condition then is the highest current $I_{0 / \mathrm{MAX}}$ combined with the closest distance $s_{a}$ possible. [...].

but they are so rare and would cause negligible material damage or outages to the system that would be tolerable or would cost more for the system to be installed.

Fig. 10 illustrates the equivalent area of a given block size arrangement without a fence for all lightning currents. While Fig. 11 does the same only for the PV power plant area normalized. By increasing the size of the park, while according to Fig. 10, the $A_{e q}$ increases proportionally with this, in the case of Fig. 11, this is reversed, and it decreases when normalized to the area. Imagine that the PV park is infinite, then the following relation will be true:

$A_{e q}\left[\mathrm{~m}^{2}\right]=A_{\mathrm{PV}}\left[\mathrm{m}^{2}\right]$.

That is, in theory, just as many lightning strikes hit the PV park as they would hit the same area if there was nothing there. This is a relatively strong statement, but do not forget that such a system can only exist in theory, and we do not deal with systems of random finite extent in my dissertation either. But this line of reasoning also predicts the complex physical processes behind it, and the results of the resulting PMAS calculation, what value it will and should approach in the real, practical situation as well. 


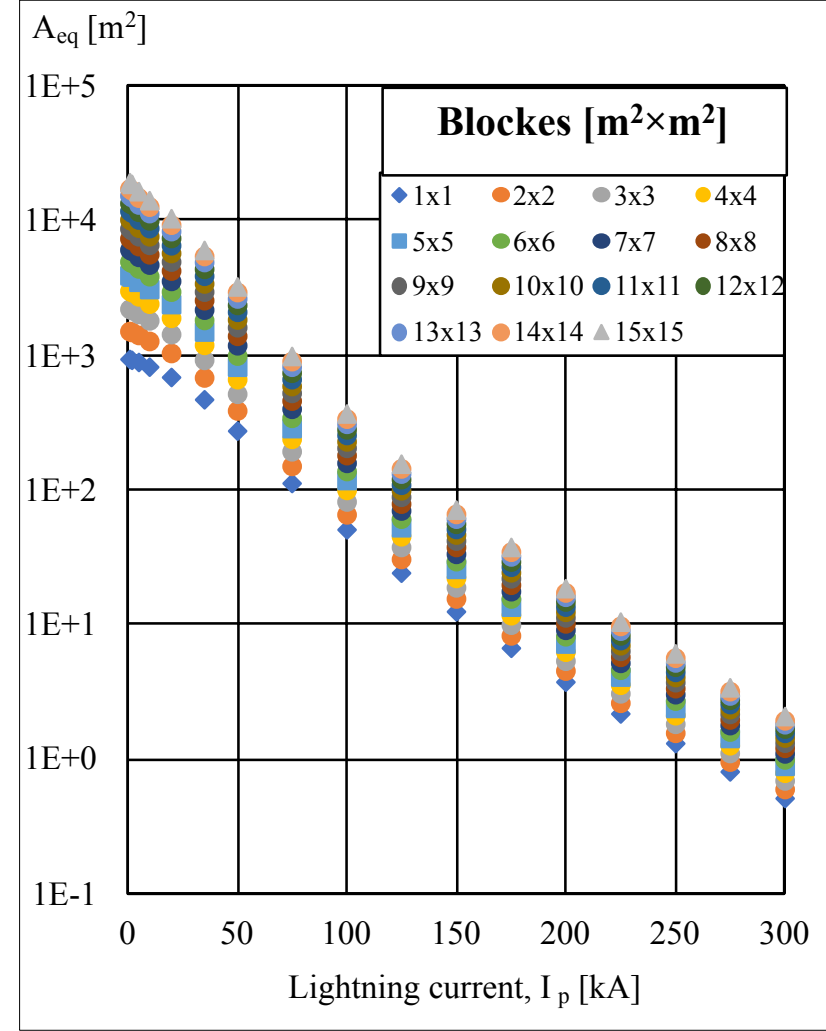

Fig. 10 Results of PMAS calculation for PV plants of different sizes. The equivalent area as a function of the occurrence of the lightning peak.

Returning to the original line of reasoning, in the case of the current values found in the standard as limit values, a kind of limit value must be used, below/above which the sub-value is not considered to be classified in the given Lightning Protection Level (LPL). The easiest way to link this to the frequency is as follows:

$f=1 / N_{G} \cdot A_{e q}\left[\frac{\text { year }}{\text { lightning strike }}\right] \geq 10^{C}$,

where $C$ is depending on the classification into LPL:

- LPL I: 3;

- LPL II: 4;

- LPL III-IV: 5.

In the following, let us look at two more graphs (Fig. 12, Fig. 13). Similarly to Fig. 12 shows the value of $A_{e q}$, while Fig. 13 shows the normalized values. Here, the abscissa contains the block sizes, and the individual curves belong to the distribution of the given lightning currents. As before, the same trend could be seen here.

In the Fig. 14, changing the block sizes as a function of the distribution of each lightning current peak, the number of lightning strikes were plotted in the PV park compared to the case without the security fence in

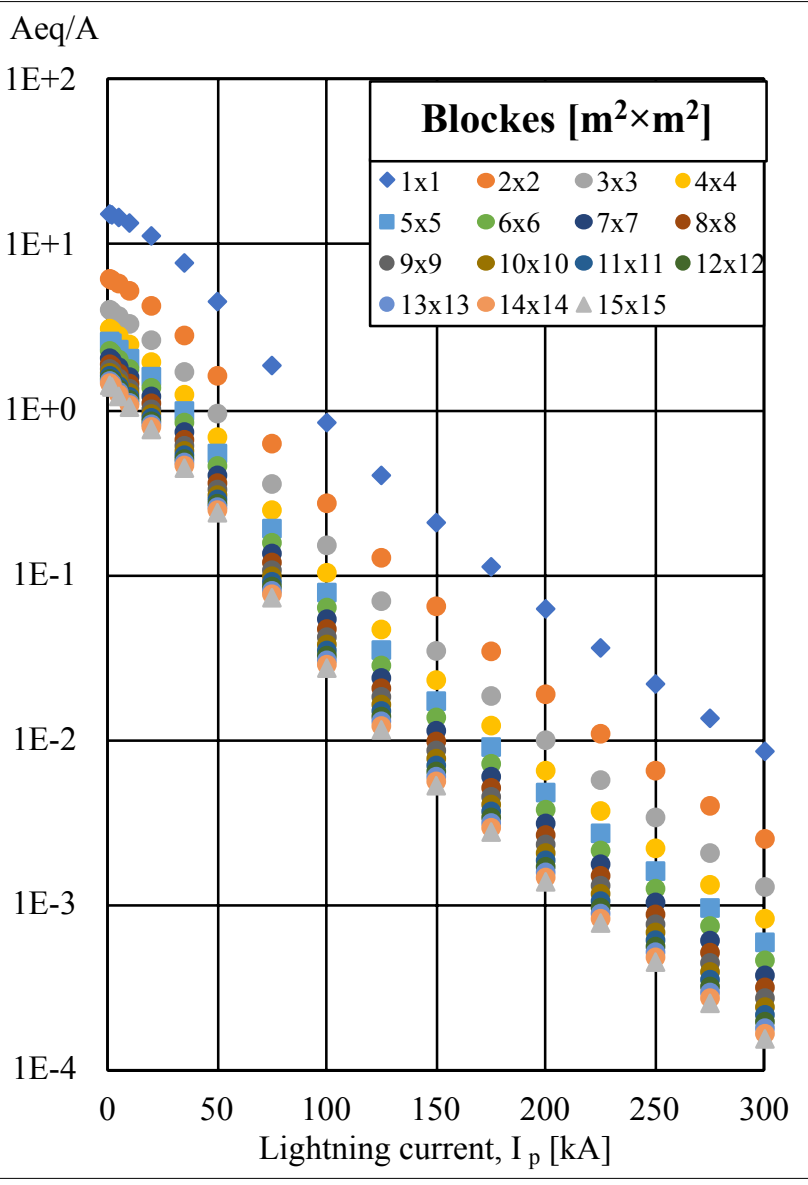

Fig. 11 Results of PMAS calculation for PV plants of different sizes.

The normalized value of the equivalent area as a function of the occurrence of the lightning peak.

proportion to the fence calculations. In the case of the values obtained in this way, in the case of larger PV parks, the rate of change in the case of smaller lightning currents $\left(I_{p}<50 \mathrm{kA}\right)$ is between $-30 \%$ and $-40 \%$, while in the case of $I_{p}<100 \mathrm{kA}$ is between $-10 \%$ and $-15 \%$, and $I_{p}<150 \mathrm{kA}$ is between $-5 \%$ and $-8 \%$.

The Fig. 15 represents the limit value of previous calculations, which gives the theoretical limit value for the shielding effect of all systems/objects that are not direct parts of the PV power plant, but, e.g., belong to the protection of property. It is important to reiterate that no matter how trivial this suggestion may seem, practice shows that all of this is not taken into account in lightning protection calculations.

\subsection{Proposal for new risk classification values based on model calculations}

Based on my calculations and the requirements of the grades formulated in the standard (Table 2), I propose the primary lightning protection of PV power plants. The first column of Table 2 contains the lightning protection rating, in addition to: 


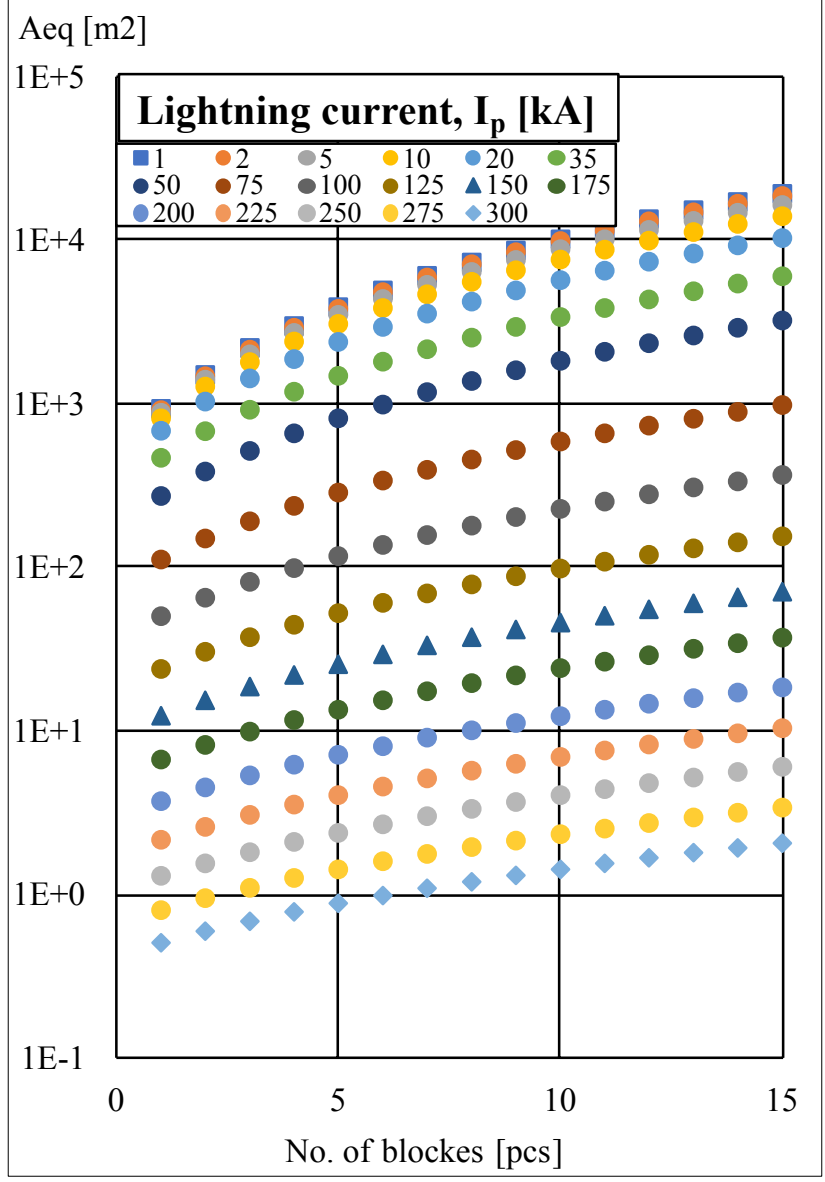

Fig. 12 Results of PMAS calculation for PV plants of different sizes. The equivalent area as a function of the blocks.

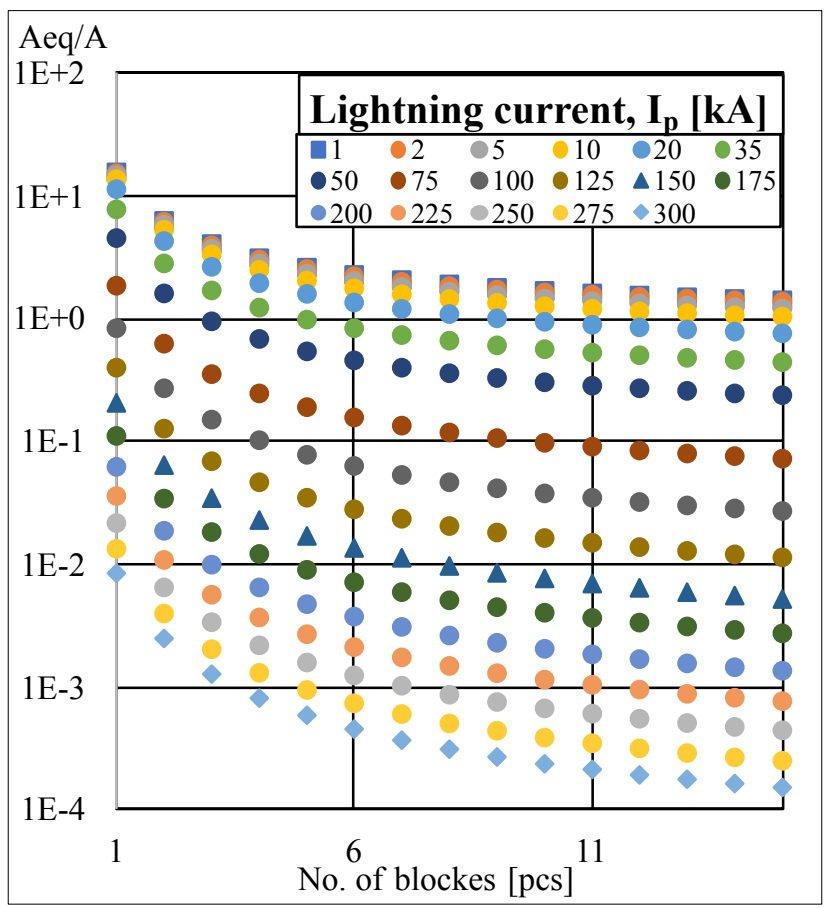

Fig. 13 Results of PMAS calculation for PV plants of different sizes. The equivalent area as a function of the blocks.

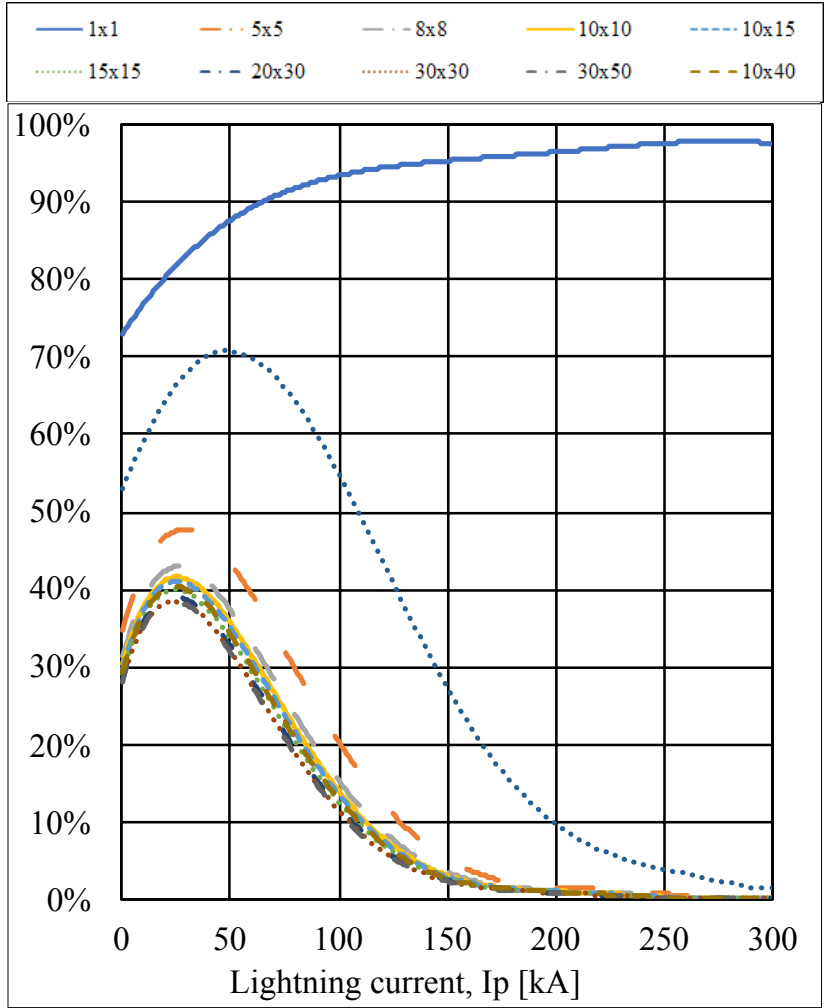

Fig. 14 Difference in PMAS calculation results (reduction of PV panel impact) in \% for PV plants of different sizes as a function of the occurrence of lightning peak.

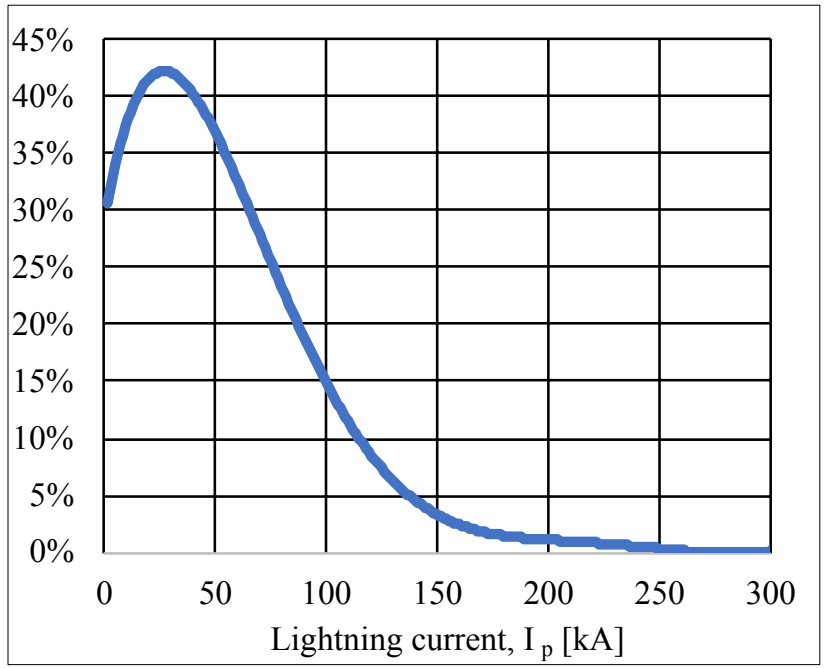

Fig. 15 Limit value of the results and differences of the PMAS calculation.

Table 2 The values of the lightning currents according to each LPL [12].

\begin{tabular}{lcc}
\hline LPL & $\begin{array}{c}\text { Smallest lightning current, } \\
I_{p}[\mathrm{kA}](>P[\%])\end{array}$ & $\begin{array}{c}\text { Highest lightning current, } \\
I_{p}[\mathrm{kA}]\end{array}$ \\
\hline IV & $16(84)$ & 100 \\
III & $10(91)$ & 100 \\
II & $5(97)$ & 150 \\
I & $3(99)$ & 200 \\
\hline
\end{tabular}


- The smallest lightning current means the maximum value that can enter into the system. The radius of the rolling sphere for lower current values, which is the same as the orientation distance, is smaller than the radius specified for the given protection level (LPL).

- The maximum lightning current that the protection devices (air-termination system, surge protector, etc.) must withstand in the case of the selected LPL. For this current value, the protection must work as intended. This is an additional burden on the cost side.

In the previous sections, I presented four risk factors of risk calculation (Section 3). I found that the calculation of $R_{1}$ and $R_{3}$ should be omitted. $R_{2}$ value calculation does not exist under the current regulation, while $R_{4}$ should be performed in all cases if data are available for a complex economic calculation. Economic risk is the secondary lightning protection of the specifically more expensive electronic (control, inverter) and high-current equipment (converter, transformer), as well as the installation of possible primary lightning protection in the buildings serving them. PV tables - as described in Section 4 - can be considered special in terms of lightning protection. If the plant is fenced with a security fence and this fence is located close enough to the PV tables, the number of cases of a possible direct lightning strike that drops into the tables will decrease. Even in the case without a fence, it can be said that the parts more exposed to lightning are the edges of the tables, which are located on the edges of the PV park.

It can also be read from Table 2 that the maximum permissible lightning current of the lightning protection levels (LPL III and IV) most commonly used in PV parks is uniformly $100 \mathrm{kA}$. This means, as mentioned earlier, this current value must be tolerated by the protection devices. That is the construction of LPL III, which imposes stricter requirements on the cross-section and material of the drain for redundant and unscientific PV parks. PV modules cannot be considered as fine electronic devices or as sensitive devices for current and future goods.

Fig. 16 shows that in the two cases, if the security fence is taken into account or not, how the sum changes in case AEQ (equivalent area, $N_{G}=1$ ). The difference can be said to be minimal $(<5 \%)$, but the same only the number of

\section{References}

[1] IRENA "Renewable Capacity Statistics 2017", [online] Available at: https://www.irena.org/publications/2017/Mar/RenewableCapacity-Statistics-2017 [Accessed: 11 September 2020]

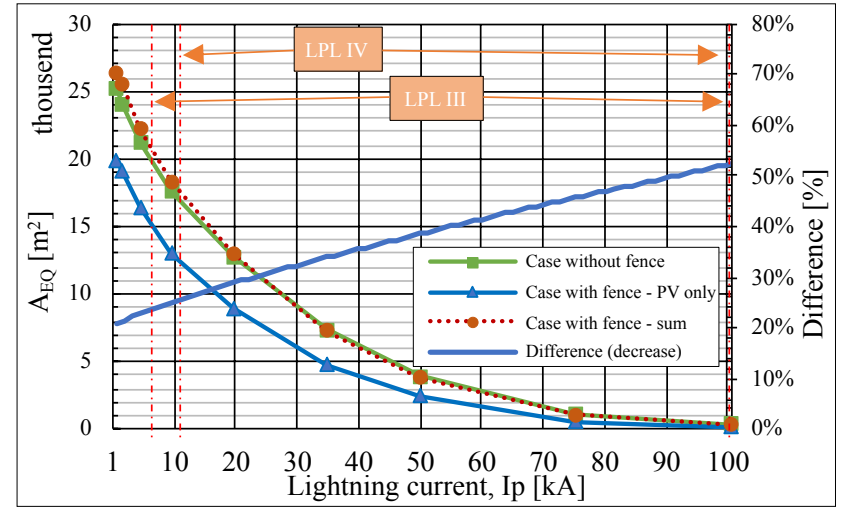

Fig. 16 The results of the PMAS calculation and the difference between the two cases in $\%$ for a PV park with $8 \times 12 \mathrm{PV}$ tables as a function of the peak currents. The LPLs are shown.

lightning strikes on the PV park is around $10 \%$ in the range of 10 to $16 \mathrm{kA}$, which is enough to avoid having to build an LPS of a higher classification level.

\section{Conclusion}

In order to avoid damage and provide effective lightning protection, I have shown that security fences, poles holding security cameras, lighting poles, and other non-negligible objects should be considered part of primary (external) lightning protection systems. In this way, according to the results of my calculations and case studies, the level of lightning protection from LPL III can reduce one class to LPL IV, which is the most commonly used classification.

I also found that if the PV power plant (based on its size, floor area, or capacity) is below a certain limit, it is not necessary to build primary protection. This size limit can be verified by performing a PMAS calculation. In these cases, a calculation must also be made to determine the attractive space of objects located in or around the power plant (e.g., objects belonging to property protection systems). A specific boundary cannot be given because the $N_{G}$ value characteristic of the geographical coordinates also varies as a function.

\section{Acknowledgment}

Supported by the ÚNKP-20-4 New National Excellence Program of the Ministry for Innovation and Technology from the source of the national research, development and innovation fund.

[2] IRENA "Renewable Capacity Statistics 2020", [online] Available at: https://www.irena.org/-/media/Files/IRENA/Agency/ Publication/2020/Mar/IRENA_RE_Capacity_Statistics_2020.pdf [Accessed: 11 September 2020] 
[3] Hannig, M., Hinrichsen, V., Hannig, R., Brocke, R. "An Analytical Consideration on The Striking Probability and The Total Amount of Strikes to Simple Structures According to Standardized Regulations", In: 32nd International Conference on Lightning Protection, Shanghai, China, 2014, pp. 1151-1158. https://doi.org/10.1109/ICLP.2014.6973339

[4] Christodoulou, C. A., Ekonomou, L., Gonos, I. F., Papanikolaou, N. P. "Lightning protection of PV systems", Energy Systems, 7(3), 2016, pp. 469-482.

https://doi.org/10.1007/s12667-015-0176-2

[5] Rousseau, A., Gruet, P. "Application of IEC 62305-2 in France on various plants Proposals for improvements", In: 28th International Conference on Lightning Protection, ICLP, Kanazawa, Japan, 2006, pp. 1235-1239.

[6] Tóth, Z., Kiss, I., Németh, B. "Effect of near wind turbines on the risk of lightning stroke on overhead lines", In: International Colloquium on Lightning and Power Systems, CIGRÉ, Ljubljana, Slovenia, 2017.

[7] Tóth, Z., Kiss, I., Németh, B. "Some Significant Problems of Lightning Protection in Flexible Energy Systems", In: CamarinhaMatos, L., Adu-Kankam, K., Julashokri, M. (eds.) Technological Innovation for Resilient Systems, Springer, Cham, Switzerland, vol. 521, 2018, pp. 293-299. https://doi.org/10.1007/978-3-319-78574-5_28

[8] Horváth, T. "Computation of lightning protection, Cargese Lectures in Physics", John Wiley \& Sons Inc., New York, USA, 1991.
[9] Horváth, T., Pankasz, L. "Ermittung der Wahrscheinlichkeiten von Nahe- und Seiteneinschläge bei Fernsehturm Moskau durch Modellversuche" (Determination of The Probabilities of Near and Side Strikes at The Moscow Television Tower through Model Tests), In: 14. Internationale Blitzschutzkonferenz, Gdansk, Poland, 1978, Paper number: 12. (in German)

[10] Horváth, T. "Concept of standardizing the lightning protection of structures", In: 31st International Conference on Lightning Protection, Vienna, Austria, 2012, pp. 1-7. https://doi.org/10.1109/ICLP.2012.6344229

[11] Golde, R. H. "Lightning Protection", Arnold (Publishers) Ltd., London, UK, 1973.

[12] International Electrotechnical Commission "IEC/EN 62305:2010 Protection against lightning", IEC, Geneva, Switzerland, 2010.

[13] Rousseau, A., Kern, A. "How to deal with environmental risk in IEC 62305-2", In: 32nd International Conference on Lightning Protection, Shanghai, China, 2014, pp. 521-527. https://doi.org/10.1109/ICLP.2014.6973180

[14] Tóth, Z., Kiss, I., Kálecz, G., Németh, B. "A fotovoltaikus, megújuló erőmúvek primer villámvédelmi kérdései" (The Primer Lightning Protection of Renewable Power Plants), In: X. Mechwart András Ifjúsági Találkozó, Budapest, Hungary, 2020, pp. 49-53. (in Hungarian) https://doi.org/10.5281/zenodo.4054032

[15] Horváth, T. "Villámhárítók védőhatásának vizsgálata kismintán" (Investigation of the protective effect of lightning rods on a small sample), PhD dissertation, BME, 1960. (in Hungarian) 